\section{Correspondence on 'Five-year treat-to-target outcomes after methotrexate induction therapy with or without other csDMARDs and temporary glucocorticoids for rheumatoid arthritis in the CareRA trial'}

The 5 -year follow-up data of the Care-RA cohort are interesting. ${ }^{1}$ However, a few points merit consideration and clarification.

Findings in the high-risk group reaffirm the fact that upfront combination disease-modifying antirheumatic drugs (DMARDs) are not needed even in patients of rheumatoid arthritis (RA) with poor prognostic factors, provided a treat-to-target strategy is followed. However, we wish to draw attention to the lowrisk group which compared initial methotrexate (MTX) monotherapy to MTX+prednisolone bridging (COBRA-Slim). The results in the low-risk group seem counterintuitive to previous landmark trials (including the BeSt and the TEAR) that found long-term outcomes to be essentially determined by treating-totarget, with the intensity of initial treatment only guiding the rapidity of response achieved. ${ }^{2}{ }^{3}$ However, in the CareRA-plus, the initial difference in disease activity between MTX monotherapy vs MTX+prednisolone bridging (COBRA-Slim) in the low-risk group persisted for up to 5 years-this could reignite interest in the concept of 'a time-limited window of opportunity' in early RA. ${ }^{4}$

However, it must be stressed that any conclusions in the lowrisk group should be guarded, as the numbers included in this group ( $\mathrm{n}=49$ at the start of this long-term extension study; 38 by the end of follow-up at 5 years) were too few to draw any reliable conclusions. Unfortunately, there was no MTX monotherapy arm in the high-risk group which had more patients, and thus could have better answered the question whether addition of bridging glucocorticoids to initial MTX monotherapy improves long-term outcomes in early RA, when followed by a tight step-up approach to treatment target.

Considering the little incremental response in any treatment arm after the first year, more details regarding the treatment escalation strategies followed after the protocol-specified two step escalation (step 1 and step 2) would be insightful. We would be interested in knowing the treatment changes (switches or additions) after the protocolised first year till year 5 (in the $\sim 50 \%$ of patients who required such changes) and the final treatment patients were taking at the end of 5 years.

Nevertheless, the authors must be congratulated for their study which has reaffirmed the fact that excellent results are possible with conventional synthetic DMARDs + prednisolone in a majority of cases and biological DMARDs are required in only a minority of patients (one-fourth) with RA.

\section{Siddharth Jain, Varun Dhir (1)}

Division of Clinical Immunology and Rheumatology, Department of Internal Medicine, Post Graduate Institute of Medical Education and Research, Chandigarh, India

Correspondence to Dr Varun Dhir, Division of Clinical Immunology and Rheumatology, Department of Internal Medicine, Post Graduate Institute of Medical Education and Research, Chandigarh 160012, India; varundhir@gmail.com

Contributors SJ drafted the manuscript. VD critically reviewed and modified it. Both authors approved the final submitted version of the manuscript.

Funding The authors have not declared a specific grant for this research from any funding agency in the public, commercial or not-for-profit sectors.

Competing interests None declared.

Patient and public involvement Patients and/or the public were not involved in the design, or conduct, or reporting, or dissemination plans of this research.

Patient consent for publication Not required.

Provenance and peer review Not commissioned; internally peer reviewed.

(C) Author(s) (or their employer(s)) 2021. No commercial re-use. See rights and permissions. Published by BMJ.

\section{Check for updates}

To cite Jain S, Dhir V. Ann Rheum Dis Epub ahead of print: [please include Day Month Year]. doi:10.1136/annrheumdis-2021-220816

Received 22 May 2021

Accepted 25 May 2021

\section{SLinked}

- http://dx.doi.org/10.1136/annrheumdis-2021-220857

Ann Rheum Dis 2021;0:1. doi:10.1136/annrheumdis-2021-220816

ORCID iD

Varun Dhir http://orcid.org/0000-0002-3626-0694

\section{REFERENCES}

1 Stouten V, Westhovens R, Pazmino S. Five-Year treat-to-target outcomes after methotrexate induction therapy with or without other csDMARDs and temporary glucocorticoids for rheumatoid arthritis in the CareRA trial. Ann Rheum Dis 2021;29:annrheumdis-2020-219825.

2 Markusse IM, Akdemir G, Dirven L, et al. Long-Term outcomes of patients with recentonset rheumatoid arthritis after 10 years of tight controlled treatment. Ann Intern Med 2016;164:523-31

3 Moreland LW, O'Dell JR, Paulus HE, et al. A randomized comparative effectiveness study of oral triple therapy versus etanercept plus methotrexate in early aggressive rheumatoid arthritis: the treatment of early aggressive rheumatoid arthritis trial. Arthritis \& Rheumatism 2012;64:2824-35.

4 Raza $K$, Filer A. The therapeutic window of opportunity in rheumatoid arthritis: does it ever close? Ann Rheum Dis 2015;74:793-4. 